\title{
Nucleophilic 5-endo-trig Cyclization of 3,3-Difluoroallylic Ketone Enolates: Synthesis of 5-Fluorinated 2-Alkylidene-2,3-dihydrofurans
}

\author{
Takeshi Fujita, ${ }^{a}$ Kotaro Sakoda, ${ }^{\mathrm{b}}$ Masahiro Ikeda, ${ }^{a}$ Masahiro Hattori, ${ }^{a}$ Junji Ichikawa*a \\ a Division of Chemistry, Faculty of Pure and Applied Sciences, University of Tsukuba, Tsukuba, Ibaraki 305-8571, Japan \\ Fax +81(29)8534237; E-mail: junji@chem.tsukuba.ac.jp \\ b Department of Chemistry, Graduate School of Science, The University of Tokyo, Hongo, Bunkyo-ku, Tokyo 113-0033, Japan \\ Received: 11.10.2012; Accepted after revision: 08.11.2012
}

\begin{abstract}
Difluoroallylic ketones readily undergo nucleophilic 5-endo-trig cyclization through their metal enolates to afford 5-fluorinated 2-alkylidene-2,3-dihydrofurans. O-Cyclization exclusively occurred via intramolecular substitution of the vinylic fluorines.
\end{abstract}

Key words: cyclization, fluorine, alkenes, furans, 5-endo-trig, ketone enolates, vinylic substitution

gem-Difluoroalkenes (1,1-difluoro-1-alkenes) have unique reactivities toward nucleophiles, which are based on their electron-deficient and highly polarized nature. They facilitate extraordinary substitution reactions, which hardly proceed in normal alkenes. ${ }^{1}$ Difluoroalkenes readily undergo vinylic nucleophilic substitution $\left(\mathrm{S}_{\mathrm{N}} \mathrm{V}\right)$ via addition to electrophilic difluoromethylene carbons and subsequent fluoride elimination. We have already reported syntheses of ring-fluorinated heterocycles by conducting the $\mathrm{S}_{\mathrm{N}} \mathrm{V}$ reaction of difluoroalkenes in an intramolecular fashion. ${ }^{2}$ As well as $\mathrm{sp}^{3}$ heteroatom and carbon nucleophiles, ${ }^{3} \mathrm{sp}^{2}$ nucleophiles ${ }^{4}$ have also participated in the 6-endo-trig cyclization to afford six-membered heterocycles (Scheme 1, eq 1). Furthermore, the high reactivity of 1,1-difluoro-1-alkenes has even allowed normally 'disfavored' 5-endo-trig cyclization, ${ }^{5-9}$ which provides scaffolds for 2-fluoro-4,5-dihydroheteroles and 2-fluorobenzoheteroles (Scheme 1, eq 2). ${ }^{10}$ Addressing the next challenge to the 'disfavored' process, we herein demonstrate the 5-endo-trig cyclization with the metal enolates of 3,3-difluoroallylic ketones, which are $\mathrm{sp}^{2}$ atom-based ambident nucleophiles and rotationally restricted around the anionic centers (Scheme 1, eq 3). This process efficiently provides 2 -alkylidene-2,3-dihydrofurans ${ }^{11}$ by (i) constructing the heterocyclic ring and (ii) introducing a fluorine substituent and an alkylidene group onto the prescribed ring carbon.

The starting 3,3-difluoroallylic ketones are readily accessible through the following chemoselective difluoromethylenation protocol. 1,3-Ketoaldehydes $\mathbf{1}$, the precursors of 3,3-difluoroallylic ketones $\mathbf{2}$, were synthesized by the acylation of either morpholine enamines $\mathbf{3}$ or metal $N$-tertbutyl enamides prepared by deprotonation of imines 4 , followed by hydrolysis (Scheme 2$).{ }^{12}$ Finally, difluoroal-

SYNLETT 2013, 24, 0057-0060

Advanced online publication: 10.12 .2012

DOI: 10.1055/s-0032-1317709; Art ID: ST-2012-U0877-L

(C) Georg Thieme Verlag Stuttgart · New York 6-endo-trig cyclization with $\mathrm{sp}^{3}$ and $\mathrm{sp}^{2}$ nucleophiles<smiles>[Y][X]c1ccccc1C([R])=CC</smiles>

$\mathrm{Y}=-\mathrm{Z}: \mathrm{TsN}-\mathrm{CH}_{2}, \mathrm{~N}=\mathrm{CR}^{\prime}, \mathrm{O}-\mathrm{CH}_{2}, \mathrm{~S}-\mathrm{CH}_{2}, \mathrm{CR}^{\prime}=\mathrm{N}$

5-endo-trig cyclization with $\mathrm{sp}^{3}$ and $\mathrm{sp}^{2}$ nucleophiles

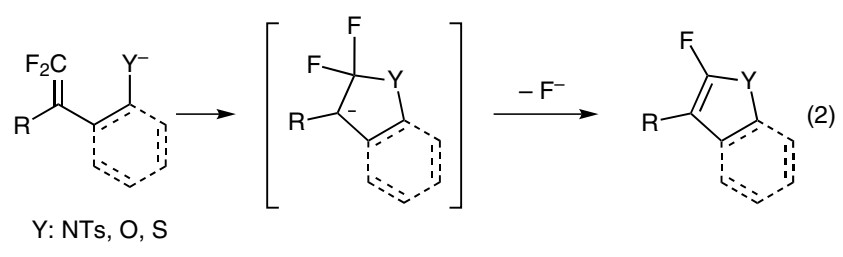

5-endo-trig cyclization with rotationally restricted $\mathrm{sp}^{2}$ nucleophiles<smiles>[R7]C([R3])=C(C(=O)C([R7])([R])C=CF)C(C)C</smiles>

Scheme 1Intramolecular cyclization of gem-difluoroalkenes

lylic ketones 2 were obtained in moderate to high yield (27-86\%) via difluoromethylenation of ketoaldehydes 1 by a triaminophosphonium difluoromethylide, generated in situ from dibromodifluoromethane and tris(dimethylamino)phosphine (Scheme 2). ${ }^{13}$ Success of the exclusively selective difluoromethylenation of $\mathbf{1}$ was due to the much higher reactivity of formyl groups compared to ketone carbonyl groups.

First, we sought bases suitable for the enolate formation and the subsequent 5-endo-trig cyclization by using difluoroallylic ketone $\mathbf{2 a}$ as a model substrate (Table 1). Lithium diisopropylamide (LDA) afforded the O-cyclization product 5a as a single isomer, albeit in low yield, while the C-cyclization product 6a was not detected at all (Table 1, entry 1). ${ }^{14}$ Two-fold increase in the amount of LDA (2 equiv) turned out to be effective for the cyclization (Table 1 , entry 2). Also, potassium hydride (1 equiv) exclusively gave 5a and drastically improved its yield up to 79\% (Table 1 , entry 3 ). As in the case of LDA, use of doubled amounts of potassium hydride ( 2 equiv) was highly effective, leading to a $91 \%$ yield of the desired dihydrofuran $\mathbf{5 a}$ (Table 1, entry 4). Thus, the nucleophilic 5-endo-trig cy- 


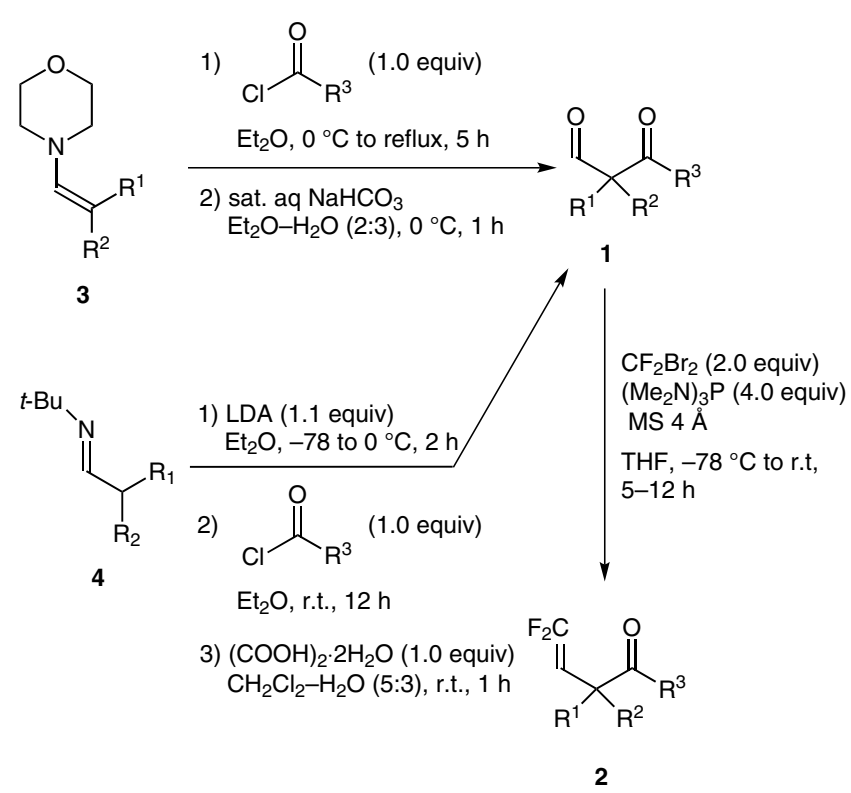

Scheme 2 Synthesis of 3,3-difluoroallylic ketones 2

clization successfully proceeded even with rotationally restricted $\mathrm{sp}^{2}$ nucleophiles in $\mathbf{2 a}$. This is likely due to the large polarization of the $\mathrm{CF}_{2}=\mathrm{C}$ moiety. ${ }^{10 a}$

Table 1 Screening of Bases Suitable for 5-endo-trig Cyclization of 2a

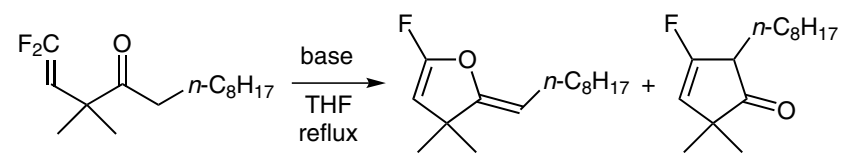
2a $5 a$ 6a

\begin{tabular}{|c|c|c|c|c|}
\hline Entry & Base (equiv) & Time & $\begin{array}{l}\text { Yield of } \mathbf{5 a} \\
(\%)\end{array}$ & $\begin{array}{l}\text { Yield of } 6 a \\
(\%)\end{array}$ \\
\hline 1 & LDA (1.0) & $5 \mathrm{~h}$ & 29 & $-{ }^{\mathrm{a}}$ \\
\hline 2 & LDA (2.0) & $4 \mathrm{~h}$ & 42 & $-^{\mathrm{a}}$ \\
\hline 3 & KH (1.0) & $2 \mathrm{~h}$ & 79 & $-{ }^{\mathrm{a}}$ \\
\hline 4 & KH (2.0) & $2 \mathrm{~h}$ & 91 & $-^{\mathrm{a}}$ \\
\hline
\end{tabular}

${ }^{a}$ Not detected.

The optimized conditions obtained above for $\mathbf{2 a}$ were successfully applied to the cyclizations of a variety of difluoroallylic ketones $\mathbf{2}$ (Table 2). ${ }^{15,16}$ Ketones $\mathbf{2 b}-\mathbf{g}$, which are dimethylated at the allylic position, gave corresponding fluorine-containing dihydrofurans $\mathbf{5 b}-\mathbf{g}$ in good to excellent yield. Difluoroallylic benzylic ketones $2 \mathbf{e}$ and $\mathbf{2 f}$ gave 2-benzylidene dihydrofurans $\mathbf{5 e}$ and $\mathbf{5 f}$, respectively. Reactions of difluoroallylic ketones $\mathbf{2} \mathbf{h}-\mathbf{j}$, which possess a cyclohexane ring at the allylic position, constructed a spirocyclic structure in $\mathbf{5 h}-\mathbf{j}$. The reactions of $\alpha, \alpha, \alpha^{\prime}, \alpha^{\prime}$-tetrasubstituted ketones $\mathbf{2 g}$ and $\mathbf{2} \mathbf{j}$ were sluggish under the same conditions. However, the longer reaction time or the
Table 2 5-endo-trig Cyclization of 3,3-Difluoroallylic Ketones 2<smiles>[R7]C([R])C(=O)C([R])([R])C=C</smiles>

Entry

${ }^{\text {a }}$ Pyridine was used as the solvent instead of THF. 
use of pyridine as the solvent instead of THF improved the yields of $\mathbf{5 g}$ or $\mathbf{5 j}$, respectively. Intriguingly, dihydrofuran derivatives $5 \mathbf{a}-\mathbf{f}$ and $\mathbf{5 i}$ were obtained as single isomers about the exo double bond, judging from ${ }^{1} \mathrm{H}$ NMR and ${ }^{13} \mathrm{C}$ NMR studies. The configurations of $\mathbf{5 a}-\mathbf{f}$ and $5 \mathbf{i}$ were assigned as $Z$-isomers by a NOESY experiment of $\mathbf{5 b} .^{17}$ This $Z$-selectivity in the formation of dihydrofurans $\mathbf{5 a}-\mathbf{f}$ and $\mathbf{5 i}$ is interpreted as follows: the $Z$-enolates seem to be generated predominantly by deprotonation of difluoroallylic ketones 2 because of steric repulsion between substituents at both of the $\alpha$ positions of the carbonyl groups in 2. The subsequent cyclization presumably proceeds through the $Z$-enolates with retention of stereochemistry.

Difluoroallylic ketones 2, as shown in Table 2, underwent 5-endo-trig $\mathrm{O}$-cyclization via their enolate forms. The reaction afforded the corresponding 2-alkylidene-5-fluoro2,3-dihydrofurans 5 without the formation of C-cyclization products, 3-fluorocyclopent-3-en-1-ones 6. Although 5-endo-trig cyclization is assigned as disfavored in Baldwin's rules, ${ }^{5}$ the reactivity of 1,1 -difluoro-1-alkenes allows the substrates to undergo such an extraordinary cyclization.

In summary, we have demonstrated that 3,3-difluoroallylic ketone enolates exclusively underwent intramolecular O-alkenylation to afford fluorinated dihydrofurans 5 bearing a $Z$-exo-alkylidene unit. The cyclization proceeded in a 5-endo-trig fashion, which is disfavored according to Baldwin's rules. In this process, a fluorine substituent was introduced selectively onto the 5-position of the 2,3-dihydrofuran scaffold. Furthermore, since fluorinated 2-alkylidene-2,3-dihydrofurans are unprecedented and highly functionalized, it is expected that these compounds would serve as parts of bioactive molecules and versatile intermediates. ${ }^{18}$

Supporting Information for this article is available online at http://www.thieme-connect.com/ejournals/toc/synlett.

\section{References and Notes}

(1) For recent reviews, see: (a) Uneyama, K. Organofluorine Chemistry; Chap. 2.3; Blackwell Publishing: Oxford, 2006. (b) Amii, H.; Uneyama, K. Chem. Rev. 2009, 109, 2119

(2) (a) Ichikawa, J. In Fluorine-Containing Synthons, ACS Symposium Series 911; Chap. 14; Soloshonok, V. A., Ed.; Oxford University Press/ACS: Washington DC, 2005. (b) Ichikawa, J. Chim. Oggi 2007, 25 (4), 54.

(3) (a) Wada, Y.; Ichikawa, J.; Katsume, T.; Nohiro, T.; Okauchi, T.; Minami, T. Bull. Chem. Soc. Jpn. 2001, 74, 971. (b) Wada, Y.; Mori, T.; Ichikawa, J. Chem. Lett. 2003, 32, 1000. (c) Mori, T.; Ichikawa, J. Chem. Lett. 2004, 33, 590. (d) Ichikawa, J.; Sakoda, K.; Moriyama, H.; Wada, Y. Synthesis 2006, 1590.

(4) (a) Ichikawa, J.; Wada, Y.; Miyazaki, H.; Mori, T.; Kuroki, H. Org. Lett. 2003, 5, 1455. (b) Ichikawa, J.; Mori, T.; Miyazaki, H.; Wada, Y. Synlett 2004, 1219. (c) Ichikawa, J.; Wada, Y.; Kuroki, H.; Mihara, J.; Nadano, R. Org. Biomol. Chem. 2007, 5, 3956.

(5) For Baldwin's rules, see: (a) Baldwin, J. E. J. Chem. Soc., Chem. Commun. 1976, 734. (b) Baldwin, J. E.; Cutting, J.;
Dupont, W.; Kruse, L.; Silberman, L.; Thomas, R. C. J. Chem. Soc., Chem. Commun. 1976, 736. (c) Baldwin, J. E.; Thomas, R. C.; Kruse, L.; Silberman, L. J. Org. Chem. 1977, 42,3846 .

(6) Ichikawa, J.; Iwai, Y.; Nadano, R.; Mori, T.; Ikeda, M. Chem. Asian J. 2008, 3, 393; and references cited therein.

(7) For recent reports on nucleophile-driven 5-endo-trig cyclization, see: (a) Anderson, J. C.; Davies, E. A. Tetrahedron 2010, 66, 6300. (b) Motto, J. M.; Castillo, Á.; Greer, A.; Montemayer, L. K.; Sheepwash, E. E.; Schwan, A. L. Tetrahedron 2011, 67, 1002.

(8) For recent reports on electrophile-driven 5-endo-trig cyclization, see: (a) Stojanović, M.; Marković, R. Synlett 2009, 1997. (b) Kalamkar, N. B.; Kasture, V. M.; Dhavale, D. D. Tetrahedron Lett. 2010, 51, 6745. (c) Saczewski, J.; Gdaniec, M.; Bednarski, P. J.; Makowska, A. Tetrahedron 2011, 67, 3612.

(9) For recent reports on radical-initiated 5-endo-trig cyclization, see: (a) Pattarozzi, M.; Ghelfi, F.; Roncaglia, F.; Pagnoni, U. M.; Parsons, A. F. Synlett 2009, 2172. (b) Yu, J.-D.; Ding, W.; Lian, G.-Y.; Song, K.-S.; Zhang, D.-W.; Gao, X.; Yang, D. J. Org. Chem. 2010, 75, 3232.

(10) For 5-endo-trig cyclization of substrates with difluoroalkene moieties, see: (a) Ichikawa, J.; Wada, Y.; Fujiwara, M.; Sakoda, K. Synthesis 2002, 1917. (b) Ichikawa, J.; Nadano, R.; Mori, T.; Wada, Y. Org. Synth. 2006, 83, 111.

(c) Ichikawa, J. Org. Synth. 2011, 88, 162. (d) Ichikawa, J.; Wada, Y.; Okauchi, T.; Minami, T. Chem. Commun. 1997, 1537. (e) Ichikawa, J.; Fujiwara, M.; Wada, Y.; Okauchi, T.; Minami, T. Chem. Commun. 2000, 1887. (f) Tanabe, H.; Ichikawa, J. Chem. Lett. 2010, 39, 248. (g) Fuchibe, K.; Takahashi, M.; Ichikawa, J. Angew. Chem. Int. Ed. 2012, 51, 12059.

(11) For selected examples of conventional synthetic methodologies for 2-alkylidene-2,3-dihydrofurans, see: (a) Tiecco, M.; Testaferri, L.; Tingoli, M.; Marini, F. J. Org. Chem. 1993, 58, 1349; and references cited therein . (b) Lattanzi, A.; Sagulo, F.; Scettri, A. Tetrahedron: Asymmetry 1999, 10, 2023. (c) Fang, Y.; Li, C. Chem. Commun. 2005, 3574. (d) Chen, Y.-F.; Wang, H.-F.; Wang, Y.; Luo, Y.-C.; Zhu, H.-L.; Xu, P.-F. Adv. Synth. Catal. 2010, 352, 1163. (e) Montel, S.; Bouyssi, D.; Balme, G. $A d v$. Synth. Catal. 2010, 352, 2315.

(12) For the synthesis of 1,3-ketoaldehydes from enamines, see: Kuhlmey, S.-R.; Adolph, H.; Rieth, K.; Opitz, G. Liebigs Ann. Chem. 1979, 617.

(13) For difluoromethylenation of aldehydes with dibromodifluoromethane and tris(trimethylamino)phosphine, see: (a) Naae, D. G.; Burton, D. J. Synth. Commun. 1973, 3, 197. (b) Vinson, W. A.; Prickett, K. S.; Spahic, B.; deMontellano, P. R. O. J. Org. Chem. 1983, 48, 4661.

(14) Baldwin noted that when endocyclic alkylation of ketone enolates constructs five-membered rings, O-cyclization would be preferable because of an in-plane approach to enolates. The chemoselectivity in our case could be partially explained by a similar reasoning, albeit with the $\mathrm{sp}^{2}-\mathrm{CF}_{2}$ electrophile instead of $\mathrm{sp}^{3}-\mathrm{C}$ electrophiles. See: Baldwin, J. E.; Kruse, L. I. J. Chem. Soc., Chem. Commun. 1977, 233.

(15) (Z)-5-Fluoro-3,3-dimethyl-2-(2-phenylethylidene)-2,3dihydrofuran (5b)

To a suspension of KH (oil free, $46 \mathrm{mg}, 1.2 \mathrm{mmol}$ ) in THF $(11 \mathrm{~mL})$ was added 6,6-difluoro-4,4-dimethyl-1-phenylhex5-en-3-one (2b, $138 \mathrm{mg}, 0.58 \mathrm{mmol}$ ), and the mixture was heated to reflux for $2 \mathrm{~h}$. After cooling to r.t., the reaction was quenched with phosphate buffer ( $\mathrm{pH} 7)$. Organic materials were extracted with $\mathrm{Et}_{2} \mathrm{O}$ three times. The combined extracts 
were washed with brine and dried over $\mathrm{MgSO}_{4}$. After removal of the solvent under reduced pressure, the residue was purified by TLC on silica gel (EtOAc-hexane, 1:5) to give $\mathbf{5 b}(122 \mathrm{mg}, 97 \%)$ as a colorless oil. ${ }^{1} \mathrm{H}$ NMR (500 $\left.\mathrm{MHz}, \mathrm{CDCl}_{3}\right): \delta=1.26\left(\mathrm{~d}, J_{\mathrm{HF}}=1.1 \mathrm{~Hz}, 6 \mathrm{H}\right), 3.45(\mathrm{~d}, J=$ $7.5 \mathrm{~Hz}, 2 \mathrm{H}), 4.20\left(\mathrm{~d}, J_{\mathrm{HF}}=5.4 \mathrm{~Hz}, 1 \mathrm{H}\right), 4.73(\mathrm{td}, J=7.5 \mathrm{~Hz}$, $\left.J_{\mathrm{HF}}=3.4 \mathrm{~Hz}, 1 \mathrm{H}\right), 7.18-7.22(\mathrm{~m}, 3 \mathrm{H}), 7.27-7.30(\mathrm{~m}, 2 \mathrm{H})$. ${ }^{13} \mathrm{C}$ NMR $\left(126 \mathrm{MHz}, \mathrm{CDCl}_{3}\right): \delta=30.1\left(\mathrm{~d}, J_{\mathrm{CF}}=2 \mathrm{~Hz}\right), 30.9$, $44.2\left(\mathrm{~d}, J_{\mathrm{CF}}=2 \mathrm{~Hz}\right), 79.7\left(\mathrm{~d}, J_{\mathrm{CF}}=8 \mathrm{~Hz}\right), 99.4,125.9,128.2$, $128.4,141.0,157.5\left(\mathrm{~d}, J_{\mathrm{CF}}=276 \mathrm{~Hz}\right), 160.6\left(\mathrm{~d}, J_{\mathrm{CF}}=3 \mathrm{~Hz}\right)$. $\left.{ }^{19} \mathrm{~F} \mathrm{NMR} \mathrm{(470} \mathrm{MHz,} \mathrm{CDCl}_{3}\right): \delta=46.2$ (s). IR (neat): 3028 , 2970, 2931, 1801, 1726, 1703, 1454, 1279, 1219, 1126, $1088,993,976,748,698 \mathrm{~cm}^{-1}$. Anal. Calcd for $\mathrm{C}_{14} \mathrm{H}_{15} \mathrm{FO}: \mathrm{C}$, 77.04; H, 6.93. Found: C, 76.80; H, 7.16\%.

(16) 3,3-Disubstituted 5-fluoro-2-alkylidene-2,3-dihydrofurans 5 are air- and heat-stable.
(17) In the NOESY experiment of dihydrofuran $\mathbf{5 b}$, substantial correlation between the methyl protons and the vinylic proton $\mathrm{H}^{\mathrm{a}}$ was observed. No NOE correlation was detected between the methyl protons and the allylic protons $\mathrm{H}^{\mathrm{b}}$ (Figure 1).

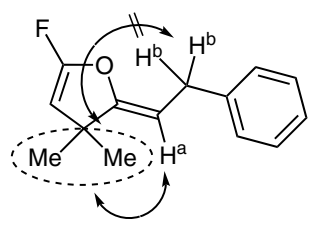

(Z)-5b

Figure 1 NOE correlation between protons in dihydrofuran $\mathbf{5 b}$

(18) For a review on bioactivities of fluorinated compounds, see: Müller, K.; Faeh, C.; Diederich, F. Science 2007, 317, 1881. 